\title{
Artikel
}

\section{Waarom een tweesporenbeleid niet spoort met het recht op onderwijs}

\author{
Het IVRPH en het recht op 'inclusief onderwijs'
}

\author{
J. Schoonheim JD, LL.M*
}

\section{Inleiding}

'Recognition of inclusion as the key to achieving the right to education has strengthened over the past 30 years, and is enshrined in the Convention on the Rights of Persons with Disabilities.'

Het Internationaal Verdrag inzake de Rechten van Personen met een Handicap (IVRPH) is na lang wachten en na wat voor sommigen leek eindeloos beraad, op 14 juli 2016 in Nederland in werking getreden. ${ }^{2}$ Voor velen was dit een feest. Veel landen hadden het verdrag al eerder geratificeerd; ${ }^{3}$ al in 2007 heeft de toenmalige Nederlandse regering getekend. ${ }^{4} \mathrm{Na}$ bijna tien jaar onderzoek naar de verplichtingen en mogelijke kosten en effecten van ratificatie van het verdrag, is het nu zover. Het IVRPH is van kracht en het is van toepassing op vele gebieden van het leven. Het onderwijs is een van die gebieden.

Het recht op onderwijs als een recht op 'inclusief onderwijs', is het onderwerp van dit artikel. De hoofdvragen

* Jacqueline Schoonheim, JD, LL.M is zelfstandig onderzoeker en adviseur.

1. CRPD/C/GC/4, General Comment No. 4 (2016), Article 24: Right to Inclusive Education, 2 September 2016.

2. Stb. 2016, 182 (Rijkswet van 14 april 2016, houdende goedkeuring van het op 13 december 2006 te New York tot stand gekomen Verdrag inzake de rechten van personen met een handicap).

3. 166 landen hebben het verdrag geratificeerd. Zie de website van het CRPD voor nadere informatie.

4. Verdrag inzake de rechten van personen met een handicap, Trb. 2007, 169 en Trb. 2014, 113. zijn: ten eerste wat het recht op onderwijs inhoudt, zoals dat is neergelegd in het verdrag; ten tweede of het Nederlands onderwijssysteem aan de verplichtingen voldoet die nu bindende kracht hebben. Om deze vragen te beantwoorden, kijken wij eerst naar de tekst van artikel 24 IVRPH waarin het 'recht op inclusief onderwijs' gewaarborgd is. Op grond van dit artikel worden Staten verplicht om in 'inclusief onderwijs' te voorzien. Al gauw denken wij dan aan buurtscholen die toegankelijk moeten zijn voor iedereen, ongeacht achtergrond, geloof of handicap. Toegang tot wat nu in Nederland bekend staan als 'reguliere scholen', in tegenstelling tot scholen voor speciaal onderwijs. Maar gaat het daar werkelijk om? Of gaat het om meer?

Het internationale comité dat toeziet op naleving van het verdrag, het Committee for the Rights of Persons with Disabilities $^{5}$, heeft recent een advies (General Comment) opgesteld over de strekking en betekenis van artikel 24 van het verdrag. ${ }^{6}$ Dit General Comment kan ons beter doen begrijpen hoe de verplichtingen van artikel 24 ingevuld moeten worden. In deze bijdrage wordt verder ingegaan op de vraag in hoeverre het Nederlands systeem van passend onderwijs voldoet aan de eisen van het verdrag. Ten slotte wordt stilgestaan bij de vraag of de Wet gelijke behandeling op grond van handicap en chronische ziekte (WGBH/CZ) voldoende bescherming tegen discriminatie op grond van handicap in het onderwijs biedt. Dit is van belang gezien de centrale verplichting van het verdrag om gelijke behandeling te bevorde-

5. www.ohchr.org/EN/HRBodies/CRPD/Pages/CRPDIndex.aspx. Zie noot 1. 
ren en discriminatie op grond van handicap uit te bannen.

\section{Inclusie: geen nieuw begrip}

Op het internationale toneel wordt 'inclusief onderwijs' al lang besproken en in andere landen wordt het actief nagestreefd. Toch lijkt 'inclusief onderwijs' nog altijd een relatief nieuw begrip in Nederland. Sinds 1994, toen de Salamanca-verklaring ${ }^{7}$ tot stand kwam, wordt inclusief onderwijs aangewezen als de manier om onderwijssystemen in te richten. De opstellers van de Salamancaverklaring, waar Nederlandse beleidsmaker actief aan bijdroegen, verklaarden dat:

'those with special educational needs must have access to regular schools which should accommodate them within a child-centred pedagogy capable of meeting these needs. ${ }^{9}$

Dit in de overtuiging dat:

'regular schools with this inclusive orientation are the most effective means of combating discriminatory attitudes, creating welcoming communities, building an inclusive society and achieving education for all; moreover, they provide an effective education to the majority of children and improve the efficiency and ultimately the cost-effectiveness of the entire education system.'

In de afgelopen twee decennia heeft de Salamanca-verklaring met het bijbehorende Actieprogramma als toetssteen gediend voor beleid door internationale organisaties en nationale overheden. Er hebben onderwijsaanpassingen plaatsgevonden, zodat steeds meer leerlingen met een beperking toegang hebben tot inclusieve scholen. ${ }^{10}$ Deze visie is nu vastgelegd in een wettelijke norm in artikel 24 van het IVRPH. In een recente, diepgravende studie van Kruseman en Forder naar de betekenis van het recht op onderwijs van artikel 24 , zeggen de auteurs:

'De aanduiding [inclusief] is niet nieuw. Inclusie als essentieel en onontbeerlijk kenmerk van het recht op onderwijs is sinds de Salamanca-verklaring uit 1994 het uitgangspunt van het internationale recht. Dat

7. Salamanca Statement and Framework for Action on Special Needs Education, aangenomen door de World Conference on Special Needs Education, Salamanca, Spanje, 7-10 juni 1994.

8. Salamanca-verklaring, par. 2

9. Salamanca-verklaring, par. 2

10. Zie bijvoorbeeld programmering van UNICEF, de Wereldbank, maar ook de initiatieven genoemd in de thematische studie door de High Commissioner on Human Rights, 18 december 2013, A/HRC/25/29, par. 64. uitgangspunt is met de totstandkoming van het IVRPH nu positief recht geworden.'11

\section{De verplichtingen uit artikel 24 IVRPH}

Artikel 24 IVRPH verplicht het realiseren van 'een inclusief onderwijssysteem op alle niveaus'. Dit is niet een doel op zich, maar het is middel om het recht op onderwijs van mensen met een handicap te waarborgen. Met andere woorden, 'inclusie' is onlosmakelijk verbonden met het recht op onderwijs en dit vereist de inrichting van een inclusief onderwijssysteem.

Artikel 24 heeft vijf leden. Het eerste legt de verplichting om in inclusief onderwijs te voorzien als volgt vast:

'Artikel 24. Onderwijs

1. De Staten die Partij zijn erkennen het recht van personen met een handicap op onderwijs.

Teneinde dit recht zonder discriminatie en op basis van gelijke kansen te verwezenlijken, waarborgen Staten die Partij zijn een inclusief onderwijssysteem op alle niveaus en voorzieningen voor een leven lang leren en wel met de volgende doelen (nadruk auteur):

a. de volledige ontwikkeling van het menselijk potentieel en het gevoel van waardigheid en eigenwaarde en de versterking van de eerbiediging van mensenrechten, fundamentele vrijheden en de menselijke diversiteit;

b. de optimale ontwikkeling door personen met een handicap van hun persoonlijkheid, talenten en creativiteit, alsmede hun mentale en fysieke mogelijkheden, naar staat van vermogen;

c. het in staat stellen van personen met een handicap om effectief te participeren in een vrije maatschappij.'

De doeleinden van een inclusief onderwijssysteem hebben te maken met zowel de ontwikkeling van de mens en zijn of haar talenten en mogelijkheden als met het effectief kunnen participeren in de maatschappij, en niet daarbuiten of ernaast. Deze lijn wordt ondersteund door het grondbeginsel in artikel 3, onderdeel c, IVRPH, dat stelt dat het verdrag is gericht op 'volledige en daadwerkelijke participatie in, en opname in de samenleving.'

Het tweede lid van artikel 24 bevat een garantie op toegang tot het algemene onderwijssysteem, en herhaalt dat het gaat om toegang tot 'inclusief, hoogwaardig' basisen voortgezet onderwijs, zonder discriminatie op grond van handicap:

11. J.H. Kruseman, C.J. Forder, Mijn, jouw of onze school het recht op inclusief onderwijs in Nederland getoetst aan het Verdrag inzake de Rechten van Personen met een Handicap, Een juridische analyse, in opdracht van In1School, een project van de Nederlandse Stichting voor het Gehandicapte Kind (NSGK), juni 2016, p. 11. Zie het eerste hoofdstuk van deze studie voor gedetailleerde beschrijving van de ontwikkelingen in hoe het recht op onderwijs nu te verstaan is als het recht op inclusief onderwijs. 
'2. Bij de verwezenlijking van dit recht waarborgen de Staten die Partij zijn dat:

a. personen met een handicap niet op grond van hun handicap worden uitgesloten van het algemene onderwijssysteem, en dat kinderen met een handicap niet op grond van hun handicap worden uitgesloten van gratis en verplicht basisonderwijs of van het voortgezet onderwijs;

b. personen met een handicap toegang hebben tot inclusief, hoogwaardig en gratis basisonderwijs en tot voortgezet onderwijs en wel op basis van gelijkheid met anderen in de gemeenschap waarin zij leven;'

Het derde lid van artikel 24 verplicht Staten om deelname aan het onderwijs op grond van gelijkheid mogelijk te maken. Ook verplicht het Staten om passende maatregelen te nemen om dat op alle wijzen te faciliteren:

'3. De Staten die Partij zijn stellen personen met een handicap in staat praktische en sociale vaardigheden op te doen, teneinde hun volledige deelname aan het onderwijs en als leden van de gemeenschap op voet van gelijkheid te faciliteren. Daartoe nemen de Staten die Partij zijn passende maatregelen, waaronder:

a. het faciliteren van het leren van braille, alternatieve schrijfwijzen, het gebruik van ondersteunende en alternatieve communicatiemethoden, -middelen en -vormen, alsmede het opdoen van vaardigheden op het gebied van oriëntatie en mobiliteit en het faciliteren van ondersteuning en begeleiding door lotgenoten;

b. het leren van gebarentaal faciliteren en de taalkundige identiteit van de gemeenschap van doven bevorderen;

c. waarborgen dat het onderwijs voor personen, en in het bijzonder voor kinderen, die blind, doof of doof blind zijn, plaatsvindt in de talen en met de communicatiemethoden en -middelen die het meest geschikt zijn voor de desbetreffende persoon en in een omgeving waarin hun cognitieve en sociale ontwikkeling worden geoptimaliseerd.'

Daarnaast moet aandacht komen voor training van docenten, medewerkers en leidinggevenden van scholen in vaardigheden die inclusie bevorderen:

'4. Teneinde te helpen waarborgen dat dit recht verwezenlijkt kan worden, nemen de Staten die Partij zijn passende maatregelen om leerkrachten aan te stellen, met inbegrip van leerkrachten met een handicap, die zijn opgeleid voor gebarentaal en/of braille, en leidinggevenden en medewerkers op te leiden die op alle niveaus van het onderwijs werkzaam zijn. Bij deze opleiding moeten de studenten worden getraind in het omgaan met personen met een handicap en het gebruik van de desbetreffende ondersteunende communicatie en andere methoden, middelen en vormen van en voor communicatie, onderwijstechnieken en materialen om personen met een handicap te ondersteunen.'

Personen met een beperking hebben ook recht op toegang tot hoger onderwijs en alle vormen van volwassenenonderwijs, vrij van discriminatie:

'5. De Staten die Partij zijn waarborgen dat personen met een handicap, zonder discriminatie en op voet van gelijkheid met anderen, toegang verkrijgen tot algemeen universitair en hoger beroepsonderwijs, beroepsonderwijs, volwasseneneducatie en een leven lang leren. Daartoe waarborgen de Staten die Partij zijn dat redelijke anpassingen worden verschaft aan personen met een handicap.'

De bepalingen van artikel 24 moeten gelezen worden in de context van het verdrag als geheel. Een centrale doelstelling van het verdrag is participatie in een toegankelijke maatschappij op alle gebieden van het maatschappelijke leven. Goed onderwijs in inclusieve onderwijsomgevingen speelt een centrale rol om dit mogelijk te maken. De betekenis van het begrip 'inclusief onderwijssysteem op alle niveaus' wordt nader onderzocht en uitgelegd in General Comment 4 'Right to Inclusive Education'.

\section{Barrières die inclusief onderwijs belemmeren: General Comment 4}

General Comment 4 legt de onderliggende beginselen van het verdrag uit, welke barrières toegang tot inclusief onderwijs belemmeren en wat de specifieke bepalingen van artikel 24 betekenen. Binnen het bestek van dit artikel is geen ruimte om het gehele General Comment onder de loep te nemen. We bespreken twee barrières die het Comité noemt. Een belangrijke barrière gaat over de vraag door welke bril wij naar het begrip handicap kijken.

'The failure to understand or implement the human rights model of disability, in which barriers within the community and society, rather than personal impairment, exclude persons with disabilities. ${ }^{12}$

Dit is een kijk op handicap die niet overal geworteld is. Nog al te vaak wordt eenvoudig gekeken naar wat een kind niet kan, puur op basis van zijn handicap. Hier hebben we te maken met het verouderde 'medische model' van handicap. Dit betreft een kijk op handicap die vooral te maken heeft met wat iemand niet kan door een aangeboren of later opgelopen beperking. Die moest medisch te verklaren of te herleiden zijn. Pas in de laat-

12. CRPD/C/GC/4, General Comment No. 4 (2016), Article 24: Right to Inclusive Education, 2 September 2016 par. 4, lid a. 
ste decennia van de twintigste eeuw begon men vragen te stellen over de relatie tussen de medisch vastgestelde beperking en de inrichting van de omgeving. Deze vragen komen voort uit het 'sociale model' van handicap. Men begon te zien dat een rolstoel pas een probleem wordt als een deuropening niet de breedte van een rolstoel heeft, of als een vervoermiddel geen ingangen heeft die iedereen kan gebruiken. Zo is het mogelijk om te zien dat de beperking van een individu pas een handicap wordt als de omgeving niet gebouwd is met een mensbeeld in gedachten van een persoon zonder enige fysieke of verstandelijke belemmering. Als onderwijs in een gebouw met alleen trappenhuizen niet op de begane grond mogelijk is, rijst de vraag of het rechtvaardig is om het probleem bij het kind te leggen en er op te staan dat het kind naar een speciale school voor 'lot-' of 'soortgenoten' moet gaan. De grondslag van het IVRPH is het 'mensenrechtenmodel' van handicap. Dat houdt in dat de oorzaken van de barrières die mensen met een beperking tegenkomen, gezocht moeten worden in de structuren van de samenleving. Waar mogelijk moeten die structuren aangepast worden.

Een andere belangrijke barrière die in Nederland een belemmerende rol speelt in het realiseren van inclusief onderwijs, is een gebrek aan politieke wil om inclusief onderwijs te implementeren:

'Lack of political will, technical knowledge, and capacity in implementing the right to inclusive education including insufficient education of all teaching staff.' 13

Andere barrières die het Comité noemt, zijn aanhoudende discriminatie en lage verwachtingen van mensen in 'mainstream settings', een gebrek aan kennis en informatie over inclusief onderwijs, een gebrek aan data en onderzoek, ook ongepaste ('inappropriate') en inadequate financieringsmechanismen voor doeltreffende ondersteuning, alsmede een gebrek aan 'legal remedies and mechanisms to claim redress of violations.'

Ten aanzien van de normatieve inhoud van artikel 24 wordt inclusief onderwijs gezien als een 'fundamental human right of all learners' ${ }^{14}$; dit fundamentele recht komt ieder kind toe. Inclusief onderwijs is niet een recht van enkel leerlingen zonder een beperking (of andere kenmerken die de dominante groep niet wenst, zoals ras of afkomst). In feite wordt het recht op inclusief onderwijs alleen betwist door degenen die buitengesloten worden. Het is echter een recht van iedereen.

In het General Comment benadrukt het Comité dat het belang van inclusief onderwijs is dat dit het mogelijk makt andere rechten te verwezenlijken. Inclusief onderwijs heeft een scharnierfunctie. Het is:

'A means of realizing other human rights. It is the primary means by which persons with disabilities can lift themselves out of poverty, obtain the means to participate fully in their communities, and be safe-

13. Par. 4, lid e.

14. Par. 10, lid a. guarded from exploitation. It is also the primary means to achieve inclusive societies. ${ }^{15}$

Het Comité maakt een belangrijk onderscheid tussen 'exclusie', 'segregatie', 'integratie' en 'inclusie' bij het definiëren van inclusief onderwijs. ${ }^{16}$ Exclusie is uitsluiting van elk vorm van onderwijs (in Nederland kan het gaan om kinderen met een leerplichtontheffing bijvoorbeeld, of leerlingen die langdurig thuiszitten omdat er geen geschikte school gevonden kan worden).

Segregatie vindt plaats als het onderwijs voor leerlingen met een beperking wordt gegeven in aparte voorzieningen die ontwikkeld zijn specifiek voor bepaalde handicaps, afgezonderd van leerlingen zonder beperkingen. Dit zou van toepassing zijn op het Nederlandse systeem van speciaal onderwijs, waaronder ook scholen voor speciaal basisonderwijs (sbo). Die scholen geven onderwijs aan kinderen en jongeren met een beperking in aparte scholen, volledig geïsoleerd van leeftijdsgenoten zonder een beperking. Toegang tot deze scholen hangt af van een 'toelaatbaarheidsverklaring' (tlv) gebaseerd op diagnostiek en verwijst leerlingen naar scholen verdeeld in clusters volgens type handicap. Zonder een tlv is er geen toegang, en dus worden kinderen geclusterd aan de hand van leerproblematiek.

Integratie wordt beschreven als het plaatsen van een kind in een reguliere ('mainstream') school, zolang het kind zich kan aanpassen aan de gestandaardiseerde vereisten van die scholen. Het plaatsen van kinderen en jongeren in reguliere klassen zonder structurele verandering in de organisatie, het curriculum en de leerstrategieën, kan niet gezien worden als inclusie, aldus het Comité.

Wat is inclusie dan wel? Het General Comment somt negen 'kerneigenschappen van inclusief onderwijs' op. ${ }^{17}$ Die zijn alle gericht op een systeemverandering. Bij die systeemverandering worden onder andere middelen actief ingezet om 'inclusief onderwijs' te realiseren, er wordt erkend dat iedereen kan leren, de focus ligt op capaciteiten en aspiraties bij het invullen van concrete lesinhoud, leerkrachten zijn geëquipeerd en worden ondersteund om leerlingvriendelijke en -toegankelijke leeromgevingen te creëren, waarin allen zich welkom en veilig voelen. Het inclusiebegrip benadrukt een 'whole systems approach'18, een 'whole educational environment' ${ }^{19}$, met een 'whole person approach':

'Recognition is given to the capacity of every person to learn, and high expectations are established for all learners, including learners with disabilities. Inclusive education offers flexible curricula, teaching and learning methods adapted to different strengths, requirements and learning styles. (...) The education

15. Par. 10, lid c.

16. Par. 11.

17. De 'core features of inclusive education' worden uiteengezet in par. 12.

18. Par. 12, lid a - onderwijsmiddelen worden inzet om inclusief onderwijs te verwezenlijken, met inbedding van verandering in institutionele cultuur, beleid en praktijken.

19. Par. 12 , lid b-Van leidinggevenden tot ouders en leerlingen - inclusief onderwijs moet ingebed worden op alle niveaus. 
system must provide a personalized educational response, rather than expecting the student to fit the system. ${ }^{20}$

De andere zes kerneigenschappen lezen als een richtlijn voor waar de focus hoort te liggen bij de transformatie naar een inclusief onderwijssysteem. Het systeem van passend onderwijs is dat beslist niet.

\section{Passend onderwijs is niet als inclusief onderwijssysteem ingericht}

Nederland kent van oudsher een tweesporensysteem van reguliere scholen en scholen voor speciaal onderwijs. Recent is het systeem van passend onderwijs geintroduceerd met de Wet passend onderwijs (Wpo). ${ }^{21}$ De Wpo verandert de essentiële deling tussen regulier en speciaal niet. Wel is een nieuwe samenwerking tussen scholen verplicht. Zowel scholen voor primair onderwijs als scholen voor voortgezet onderwijs, ook scholen voor speciaal onderwijs, zijn verplicht tot samenwerking in samenwerkingsverbanden (swv's). ${ }^{22}$ Deze swv's verdelen rijksmiddelen voor onderwijsondersteuning aan de schoolbesturen die deel uitmaken van het swv. Ook hebben scholen nu een 'zorgplicht'. Dit betekent dat de school van aanmelding er zorg voor draagt om de angemelde leerling een passende onderwijsplaats te bieden binnen de eigen school, of als dat bewezen niet kan, dan op een andere reguliere of speciale school. Dit is afhankelijk van de onderwijsondersteuning die de leerling nodig heeft (vastgelegd in een Ontwikkelingsperspectief of OPP) en wat de school kan bieden om de ondersteuningsbehoefte op te vangen. Een aangemelde leerling mag niet verwijderd worden tot een andere school gevonden is. Elke leerling heeft recht op een passende onderwijsplek. Wat passend is, ligt in het oordeel van de scholen, en ouders die het oneens zijn mogen bezwaar maken en het geschil voorleggen aan de Geschillencommissie passend onderwijs, of verder procederen naar de rechter, of een klacht indienen bij het College voor de Rechten van de Mens. Centraal hoort te staan wat de ondersteuningsbehoefte van het kind is, los van medische labels. ${ }^{23}$

Centrale doelen van het Wpo zijn budgettaire beheersing van stijgende kosten, die gepaard gaan met een groeiend aantal verwijzingen naar het speciaal onderwijs. Belangrijk doel is ook het terugbrengen van het aantal 'thuiszitters' tot nul. ${ }^{24}$ Het verwezenlijken van

20. Par. 12, lid c.

21. Met ingang van 1 augustus 2014.

22. Er zijn in totaal 152 swv's, 77 in het basisonderwijs en 75 in het voortgezet onderwijs, zie de website voor passend onderwijs www. passendonderwijs.nl/samenwerkingsverbanden-en-gemeenten/wat-zijn -samenwerkingsverbanden/.

23. Kamerstukken I/ 2011/12, 33106, 3, p. 10

24. Kamerstukken // 2011/12, 33106, 3, p. 10. inclusief onderwijs wordt in de parlementaire geschiedenis niet genoemd. Het komt wel in de parlementaire behandeling an de orde bij de ratificatie: de regering zegt dat 'met inclusie wordt bedoeld dat niemand wordt uitgesloten van onderwijs'. ${ }^{25}$ Dit is duidelijk niet wat bedoeld wordt met 'inclusie' in het IVRPH.

Waar schiet het systeem van passend onderwijs tekort? In de analyse van Kruseman en Forder is het in stand houden van een tweesporensysteem op zich al een schending van het recht van elk kind op inclusief onderwijs. ${ }^{26}$

'Het Nederlandse onderwijssysteem is nog steeds gebaseerd op het medisch model van handicap waarbij leerlingen op basis van de classificatie van hun handicap instromen in het reguliere of het speciale onderwijs.' (p. 93)

Kruseman en Forder toetsen het recht op inclusief onderwijs binnen het systeem van passend onderwijs aan vier criteria waaraan het recht op onderwijs hoort te voldoen: is het onderwijs aanvaardbaar, flexibel, toegankelijk en beschikbaar? Deze criteria zijn in het internationaal recht ontwikkeld en worden in General Comment 4 toegepast op de verplichting in artikel 24, lid 2, onderdeel b, IVRPH, dat inhoudt dat toegang wordt gewaarborgd tot 'inclusive, quality and free primary and secondary education'. ${ }^{27}$

Qua aanvaardbaarheid, schrijven de auteurs na een grondige analyse van de ontwikkeling van het recht op onderwijs, dat 'inclusief onderwijs de enige aanvaardbare vorm van onderwijs voor leerlingen met een handicap' is. ${ }^{28} \mathrm{Zij}$ trekken de conclusie dat dit niet geldt voor alle leerlingen in Nederland, en met name niet voor kinderen met een beperking. Wat betreft flexibiliteit, is een gebrek aan flexibiliteit een gesignaleerd probleem in het systeem van passend onderwijs, dat in verband gebracht wordt met een behoorlijk aantal thuiszitters. ${ }^{29}$

'De behoefte van de leerling staat in de Wet passend onderwijs niet centraal, waardoor leerlingen in verschillende onderwijssystemen onderwezen worden, waarbij het gesegregeerde kader van het onderwijs bepalend is voor het soort onderwijs dat een leerling kan volgen. ${ }^{30}$

Er zijn wel aanknopingspunten in de wet voor maatwerk, maar in zijn geheel blijft het een systeem van segregatie. Hetzelfde geldt voor het vierde criterium, beschikbaarheid. Dit gaat over de anwezigheid van scholen in de buurt die toegerust zijn om inclusief

MvT, Goedkeuringswet, Kamerstukken // 2013/14, 33992 (R2034), 3, p. 71.

26. Kruseman en Forder, p. 93-98.

27. General Comment 4, par. 19 t/m 25, met verwijzing naar General Comment 13, The right to education in implementation of the International Covenant on Economic, Social \& Cultural Rights, CESCR E/C. 12/1999/10.

28. Kruseman en Forder, p. 94.

29. Zie bijvoorbeeld het Rapport van de Kinderombudsman, Werkt Passend Onderwijs? Stand van zaken een jaar na dato, KOM014/2015, september 2015, p. 11, 21

30. Kruseman en Forder, p. 96. 
onderwijs te geven in de zin van artikel 24. De conclusie is dat

'door het ontbreken van een inclusief onderwijsstelsel is onderwijs niet beschikbaar voor veel leerlingen met een handicap en daarmee in strijd met artikel 24.'

Zolang de politieke wil ontbreekt om een kader voor inclusief onderwijs te scheppen, blijft dit de grootste barrière voor het realiseren van toegang tot inclusief onderwijs, hetgeen een schending is van het recht op onderwijs van kinderen met een beperking.

\section{Bescherming tegen discriminatie onder WGBH/ $\mathrm{CZ}$}

Het huidige systeem mag getoetst worden aan de WGBH/CZ, waar onderwijs sinds 14 juni 2016 in de categorie 'aanbod van diensten' valt. Onderscheid op grond van handicap en chronische ziekte is verboden bij het aanbieden van of verlenen van toegang tot goederen of diensten. ${ }^{31}$ Ook de Geschillencommissie passend onderwijs is bevoegd om geschillen over toelating, verwijdering en het Ontwikkelingsperspectief te toetsen aan het $\mathrm{WGBH} / \mathrm{CZ}{ }^{32}$ Het verbieden van discriminatie en het gelijk behandelen van leerlingen met een beper-
Volgens artikel 3, lid 1, onderdeel b, WGBH/CZ is segregatie op grond van handicap in het onderwijs dus toegestaan. Op deze manier is de $\mathrm{WGBH} / \mathrm{CZ}$ in overeenstemming met het gesegregeerde onderwijsstelsel in Nederland, maar niet met het IVRPH. Artikel 5 IVRPH (het discriminatieverbod) moet gelezen worden in de context van artikel 3 IVRPH, dat de algemene beginselen van het IVRPH vastlegt. Het omvat naast non-discriminatie onder andere ook 'volledige en daadwerkelijk participatie in de samenleving'. Volgens Kruseman en Forder staat

'de uitzondering op het discriminatieverbod (...) haaks op het gelijkheidsbeginsel van het IVRPH waar het voorzieningen in stand houdt die mensen met een handicap afzonderen van de samenleving, zoals het speciaal onderwijs.' 33

Artikel 3, lid 1, onderdeel b, WGBH/CZ is daarom in strijd met internationaal recht.

$\mathrm{Er}$ is veel meer te zeggen over de bescherming geboden door het WGBH/CZ, waaronder hoe 'redelijke aanpassingen' getoetst dienen te worden in het kader van het IVRPH. Dat is een onderwerp dat in de toekomst aandacht verdient.

\section{Conclusie}

Een onderwijssysteem dat onderwijssegregatie in stand houdt, voldoet niet aan de inclusieve visie en verplichtingen die voortvloeien uit het IVRPH. Het recht op onderwijs voor kinderen met een beperking is onlosmakelijk verbonden met inclusie, met het recht om erbij te horen, niet in aparte omgevingen of lokalen, maar in dezelfde scholen. Het recht op onderwijs omvat dan ook een recht op inclusie. Het verdrag geeft aan dat inclusie verder gaat dan het meedoen in het reguliere onderwijs. Het recht op inclusief onderwijs is het recht om zich te ontwikkelen op een school in de buurt, die ieder kind welkom heet en die is toegerust om de doelstellingen van artikel 24 te vervullen. In het huidige systeem van passend onderwijs spreken we eerder van 'integratie' van kinderen met een beperking in het onderwijs. Het begrip 'segregatie' is daarnaast van toepassing op leerlingen in het speciaal onderwijs, terwijl 'exclusie' van toepassing is op kinderen en jongeren in dagbesteding of thuis. Zolang de onderwijsomgeving niet verplicht is zich aan te passen aan de behoeften van het kind, moet het kind zich aanpassen aan het systeem. Deelname aan het reguliere onderwijs is anders uitgesloten. Dit is niet de visie van het IVRPH. Een gebrek aan politieke wil om dit te veranderen is een barrière in het realiseren van inclusief onderwijs. Totdat de wetgever de doelstelling om het bestaande systeem te transformeren tot een inclusief onderwijssysteem vastlegt in wet en beleid, blijft het Nederlands onderwijssysteem een tweesporen-

33. Kruseman en Forder, p. 112 
systeem. Dat maakt het onmogelijk om het recht op onderwijs van alle (potentiële) deelnemers te garanderen. 